Modeling the distribution of odonates: from the pages of 2oth century field notes to the shapefiles of the

\title{
21st century
}

Emily L. Sandall', Claire E. Jones ${ }^{2}$, Andrew R. Deans

'Frost Entomological Museum, Penn State University, University Park, PA

${ }^{2}$ Geographical Information Systems Collaboratory, Depaul University, Chicago, IL 


\section{The Journey}
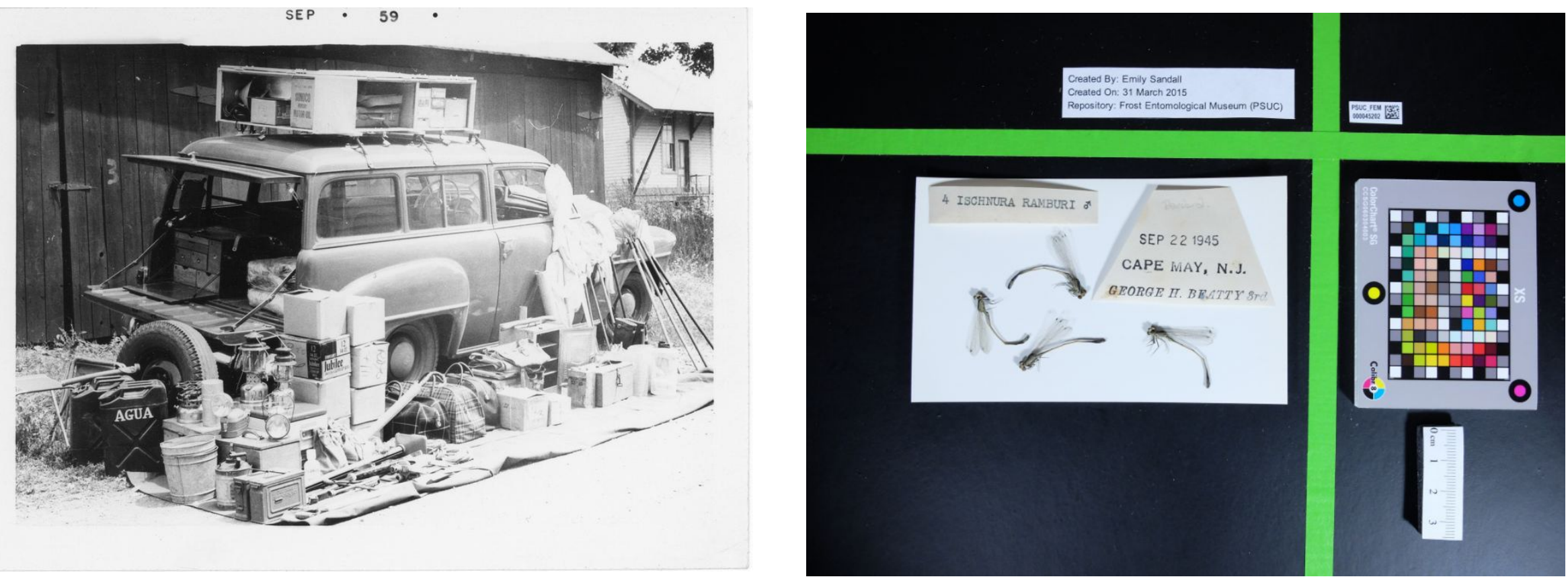


\section{Workflow}

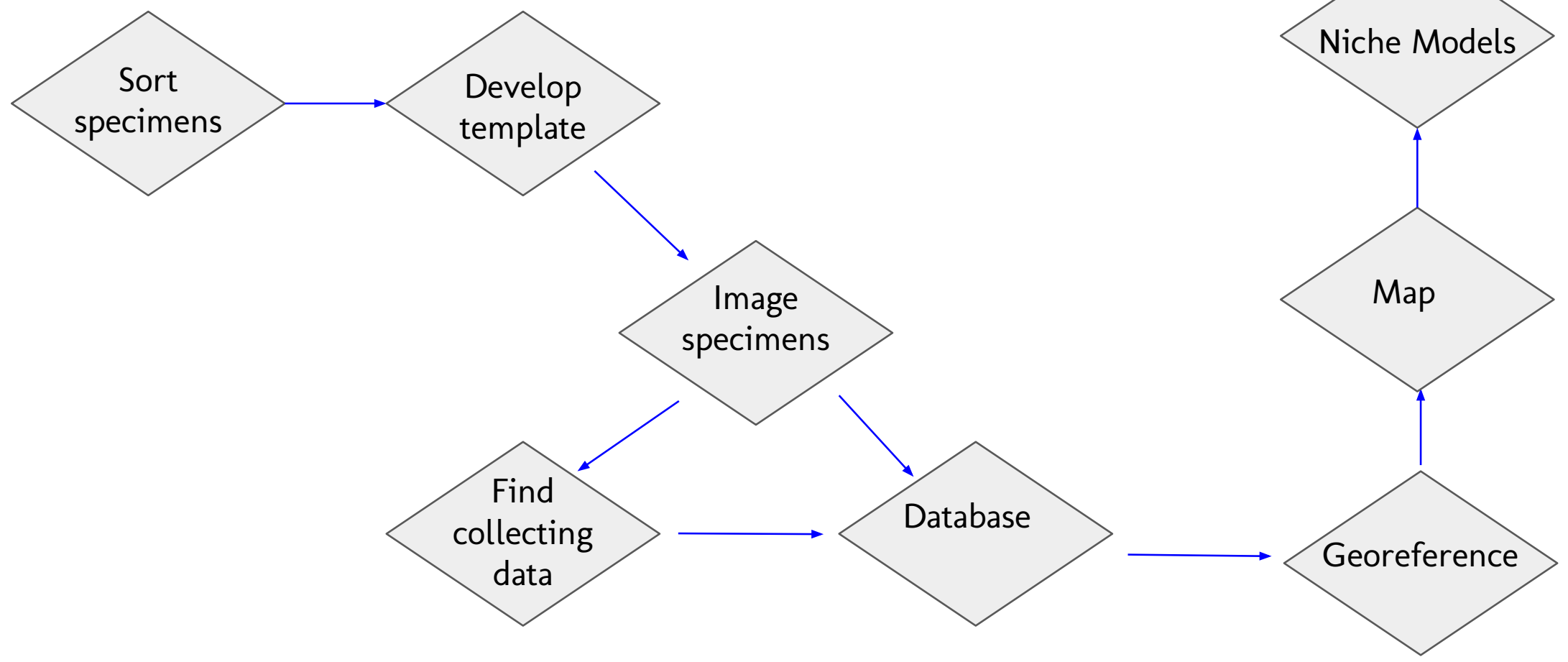




\section{The Beatty Collection}
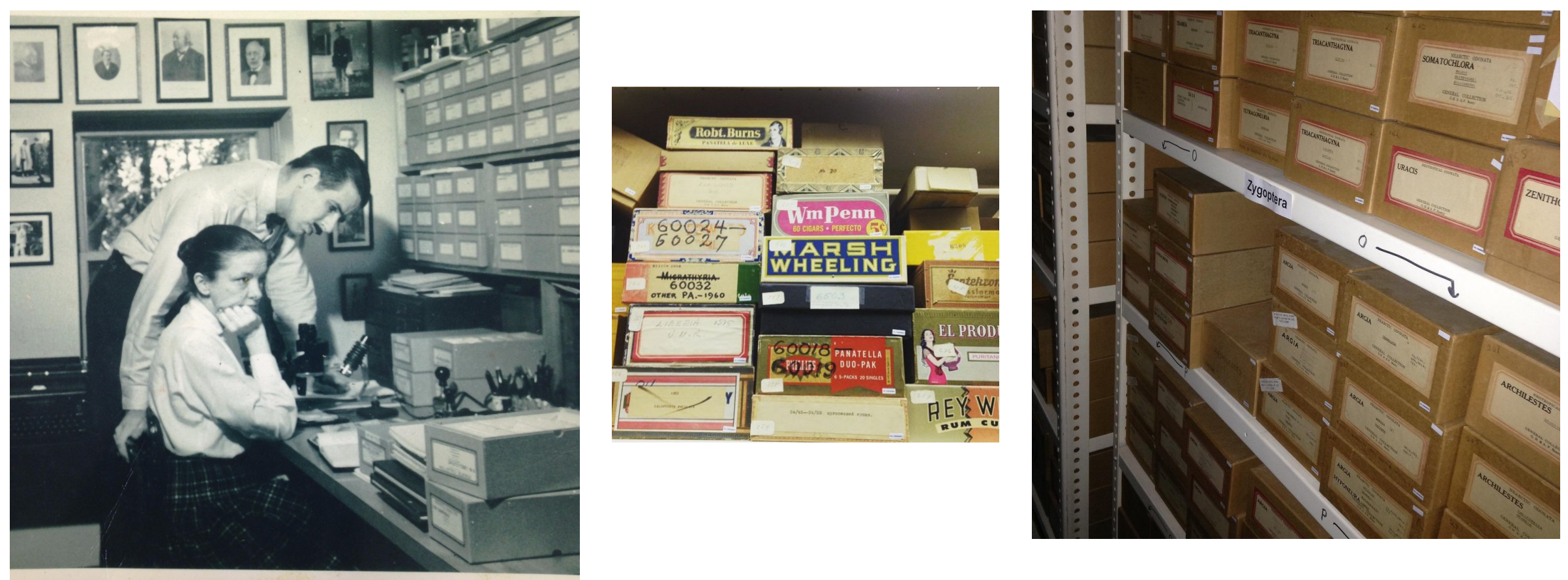


\section{Digitization}

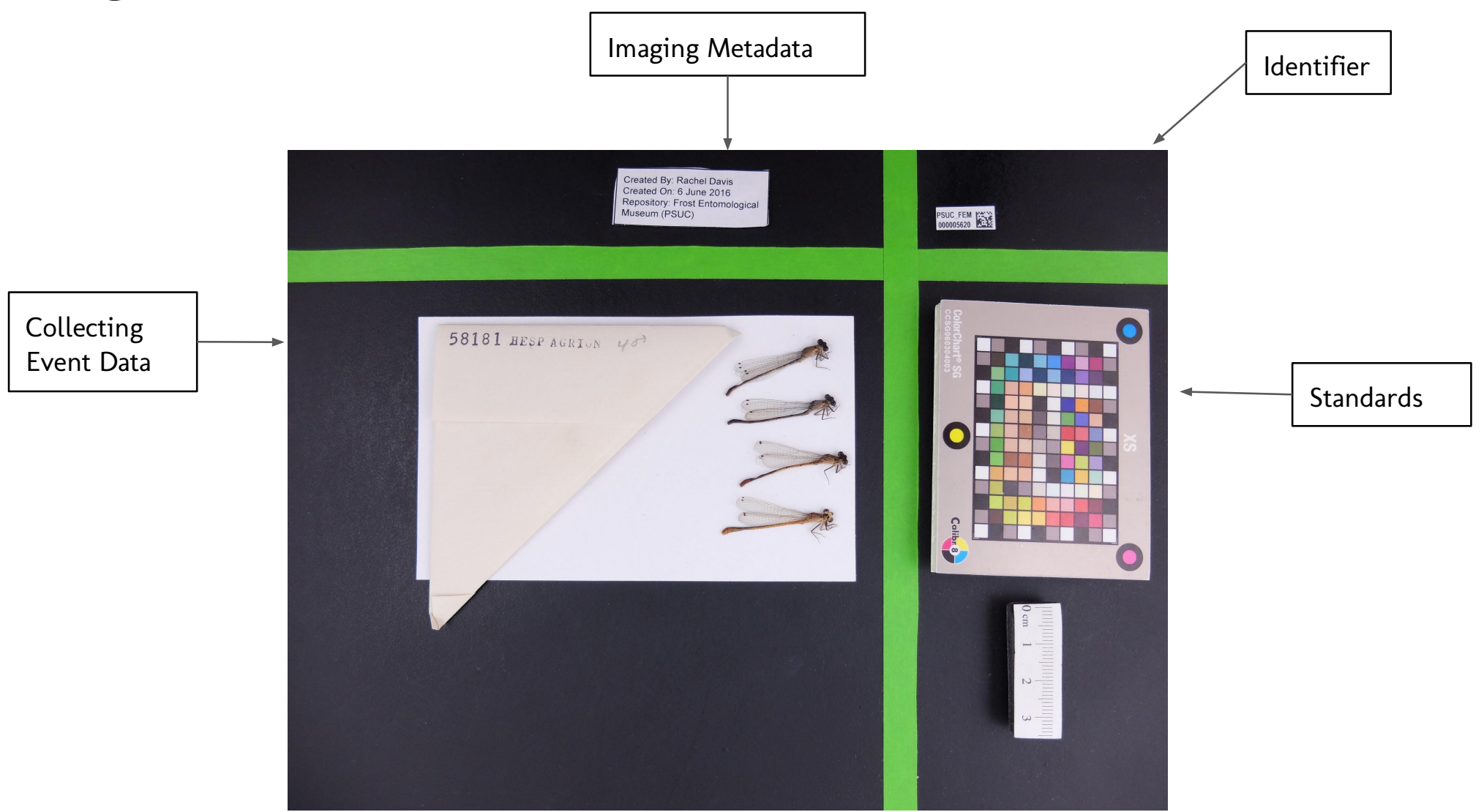




\section{Field Notes \& Associated Papers}
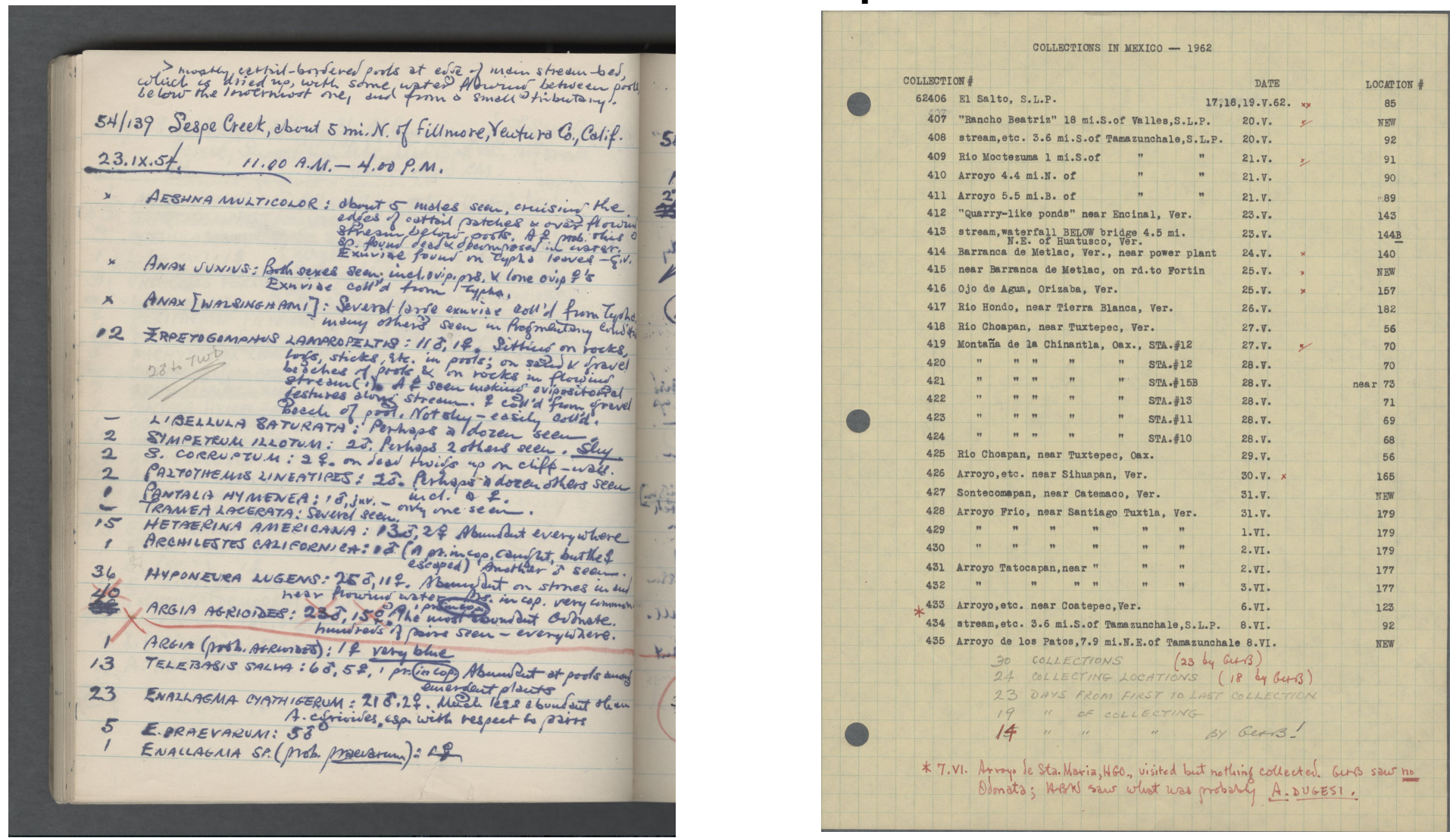


\section{Georeferencing}

\section{TODO map Sqed depiction: 16227 Original image Depiction breakdown}

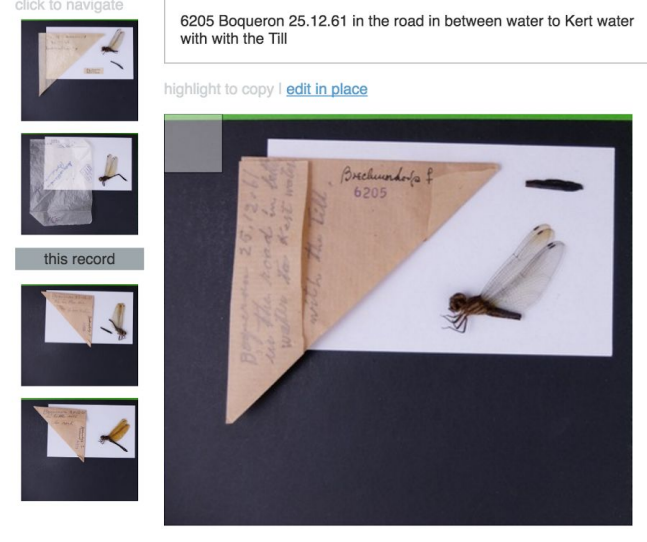

Edit collecting event

Verbatim locality

6205 Boqueron 25.12.61 in the road in between water to Ke

Geographic area

Boquerón

Namespace Identifier

Seve changes Save and next

Collecting event details

Show collecting event

Geographic area: Boquerón

Field notes:

Md5 of verbatim label:

Cached:

Verbatim label:

Print label:

Document label:

Verbatim

Verbatim locality: 6205 Boqueron 25.12.61 in the road in between water to Kert water with with the TII

Verbatim date:

Verbatim latitude:

Verbatim longitude:

Verbatim elevation:

Verbatim datum:

Verbatim geolocation uncertainty:

Verbatim trip identifier:

Verbatim collectors: 


\section{Hypotheses}

- Inclusion of the Beatty Odonata Collection data can add coverage and power to ecological niche models generated

- Digitized collections in conjunction with field notes can be combined to provide data points for distribution analyses

- Georeferenced collections data incorporated with recent specimen data can show change in distributions over time, such as northward shifts from warming temperatures 


\section{Taxa}

Argia moesta (Hagen,1861)

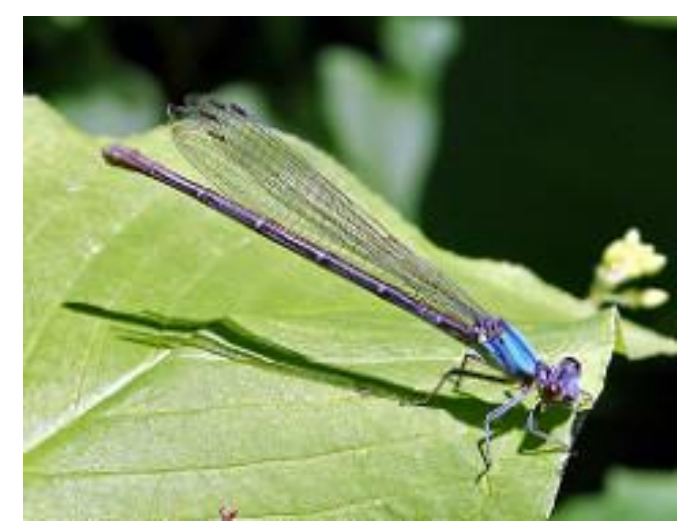

Photo by Aaron Carlson (CC BY-SA 2.0)
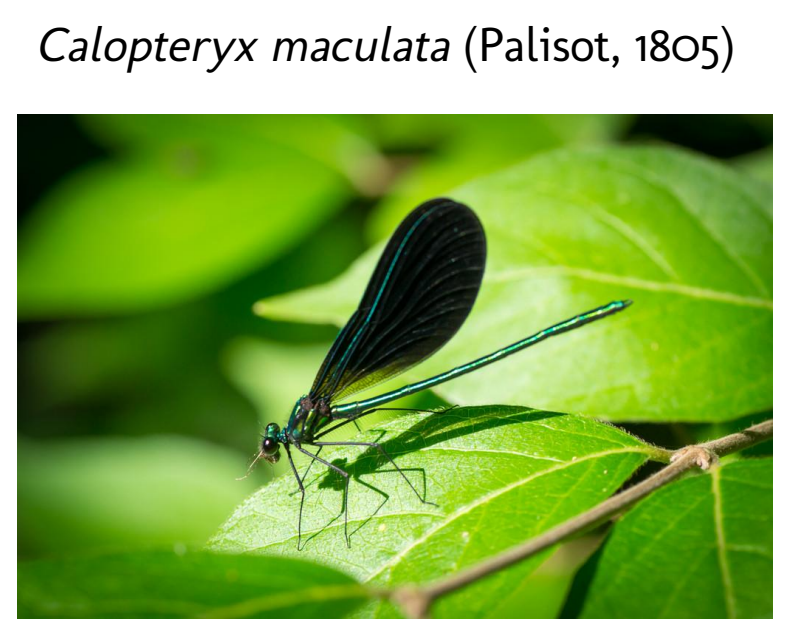

Photo by Andrew C (CC BY 2.0)
Epitheca cynosura (Say, 1839)*

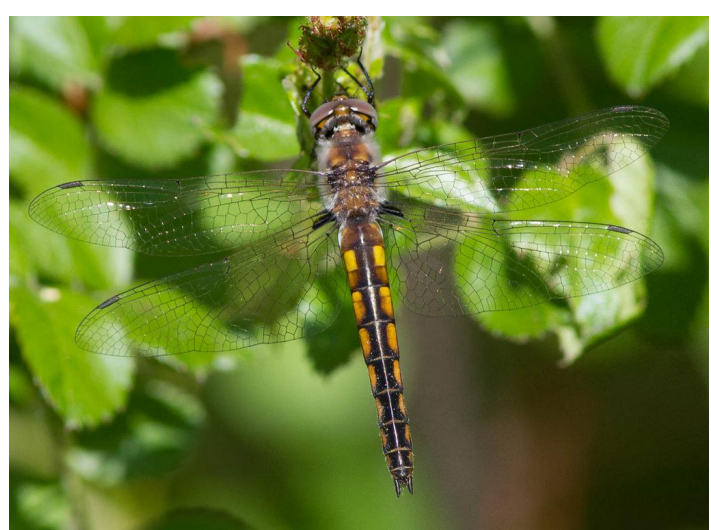

Photo by Jason Forbes (CC BY-NC-ND 2.0) 
What can we learn from ecological niche models partitioned into several time periods versus one model for all georeferenced specimens? 


\section{MaxEnt Modeling}
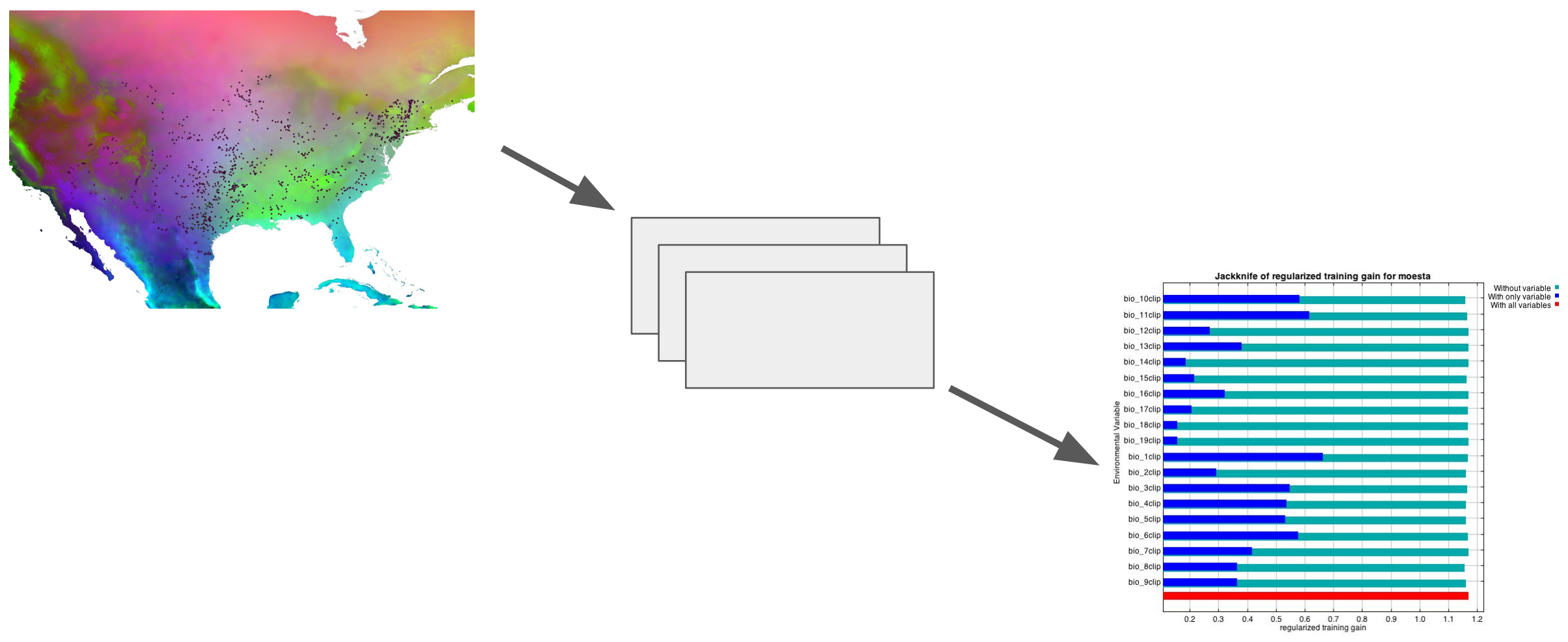


\section{Argia moesta (Coenagrionidae)}

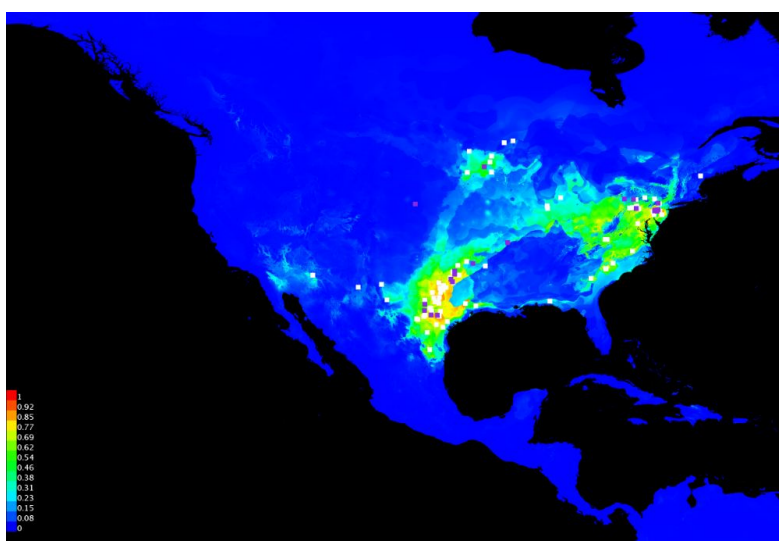

Prior to 1964

$$
n=369
$$

Variable: mean temperature of warmest quarter

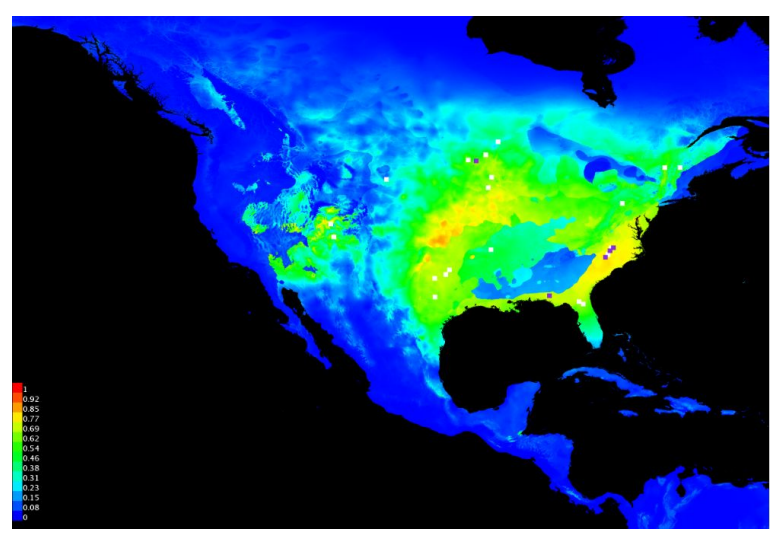

1964-1989 $n=52$

Variable: mean temperature of warmest quarter

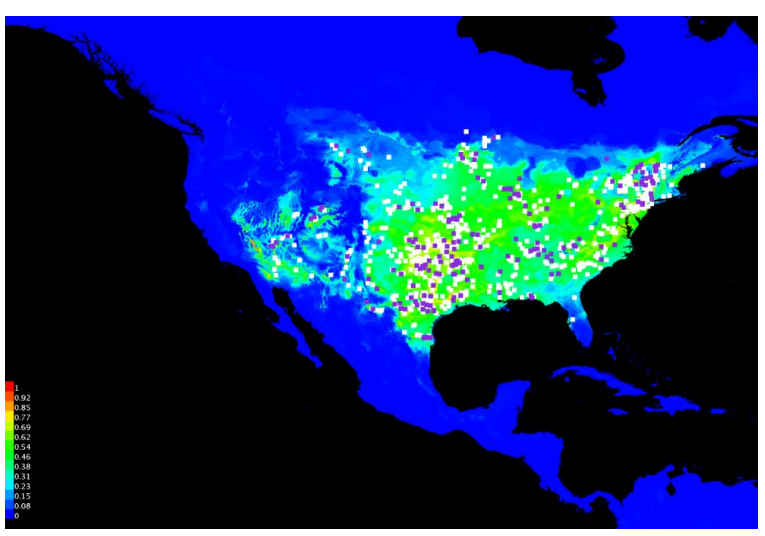

$1990-2015$ $n=1423$

Variable: mean temperature of the warmest quarter 
Argia moesta Overall

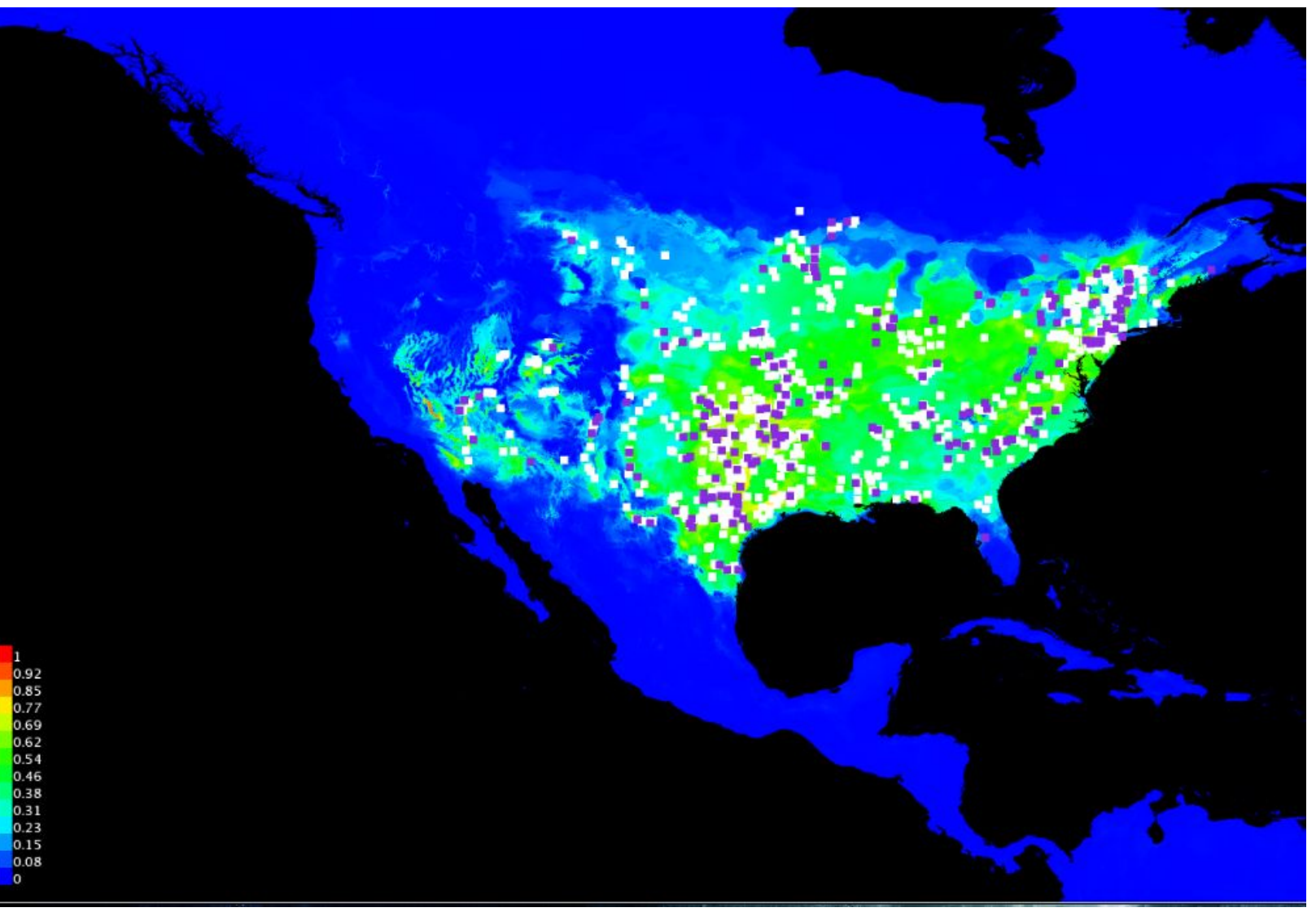




\section{Calopteryx maculata (Calopterygidae)}

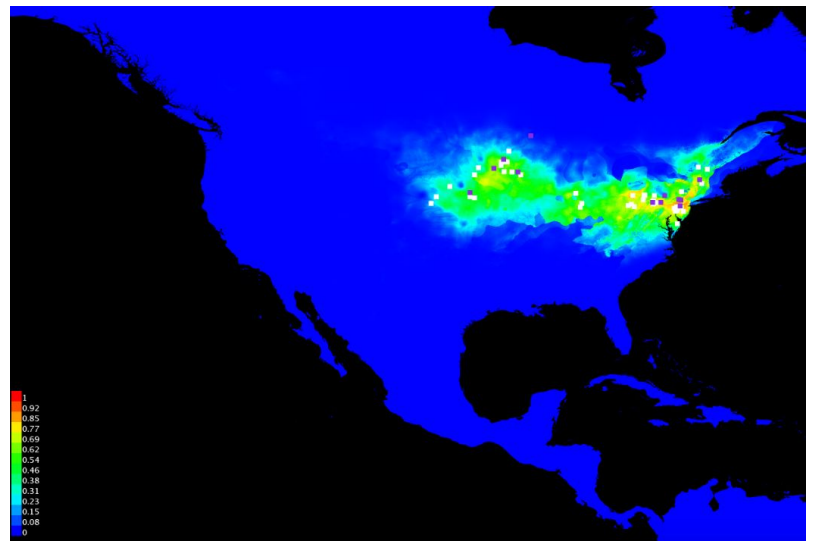

Prior to 1964

$\mathrm{n}=210$

Variable: mean precipitation of warmest quarter

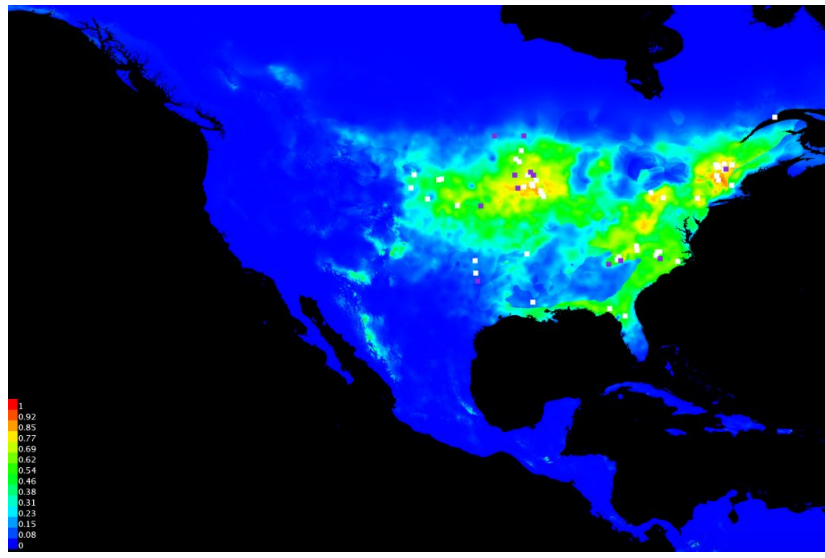

1964-1989 $n=103$

Variable: mean precipitation of warmest quarter

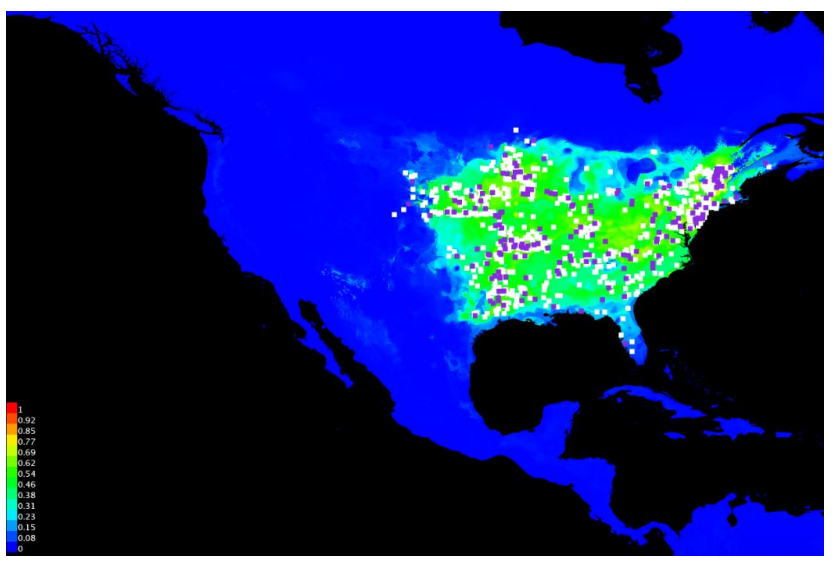

$1990-2015$ $n=1394$

Variable: mean temperature of warmest quarter 


\section{Calopteryx maculata Overall}

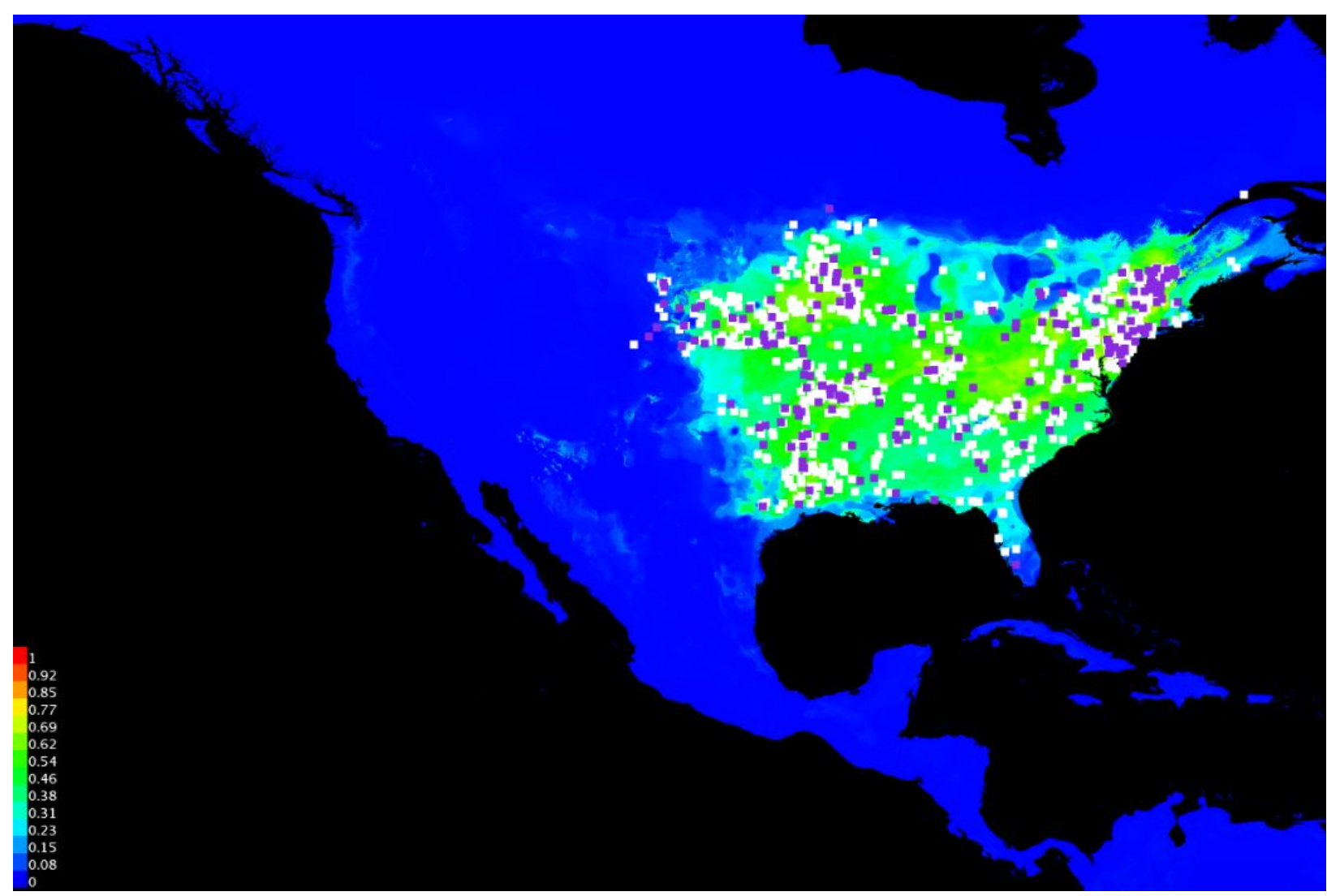




\section{Epitheca cynosura (Corduliidae)}

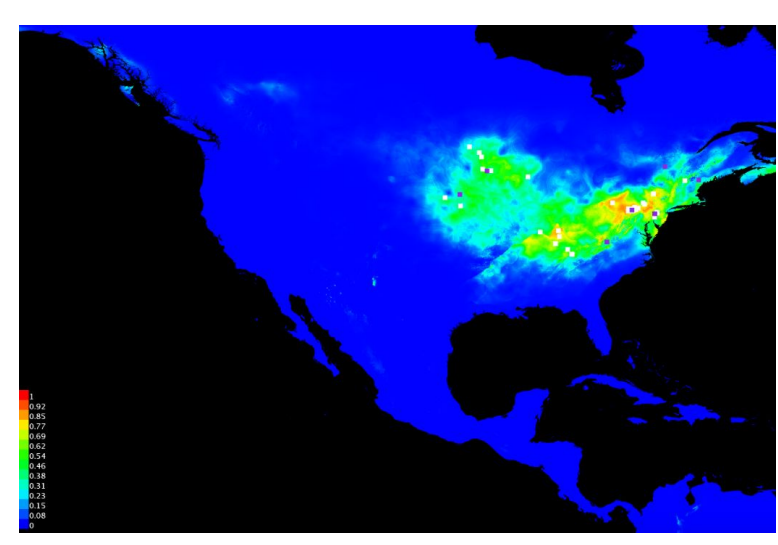

Prior to 1964

$$
\mathrm{n}=198
$$

Variable: precipitation of warmest quarter

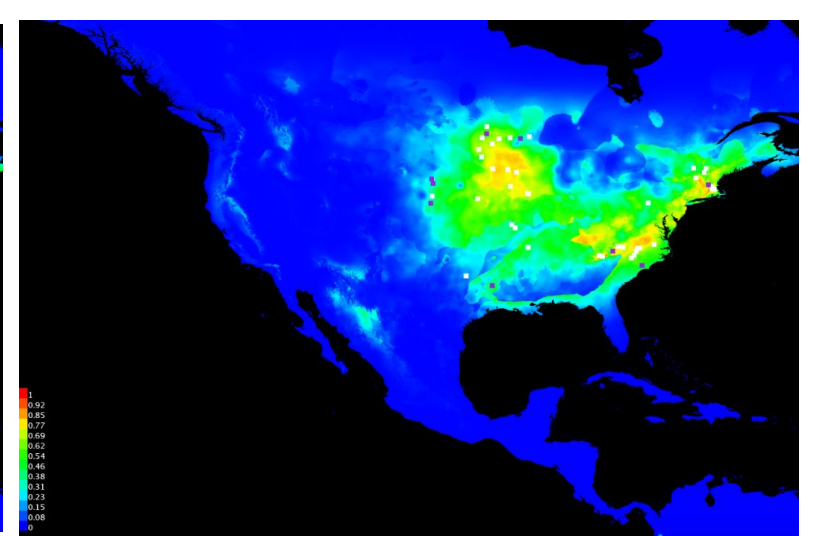

1964-1989

$\mathrm{n}=77$

Variable: precipitation of warmest quarter

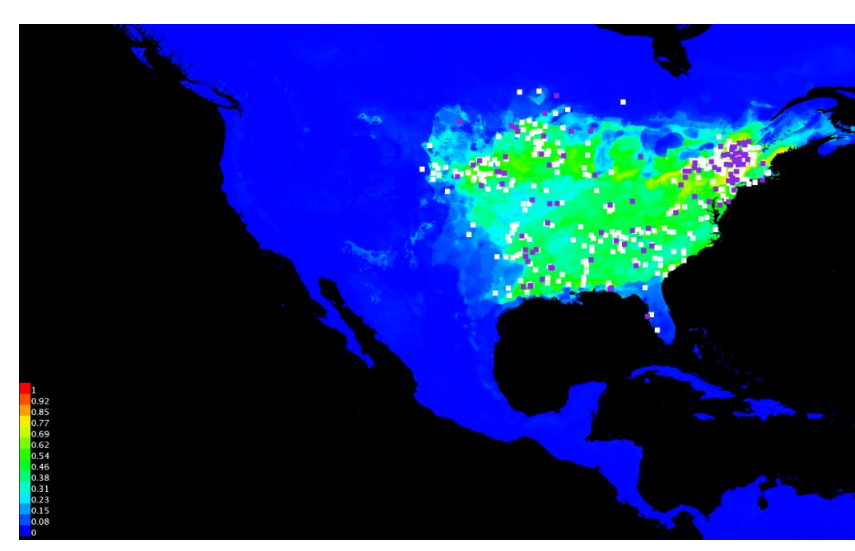

$1990-2015$

$\mathrm{n}=737$

Variables: precipitation of warmest quarter \& annual mean temperature 
Epitheca cynosura Overall

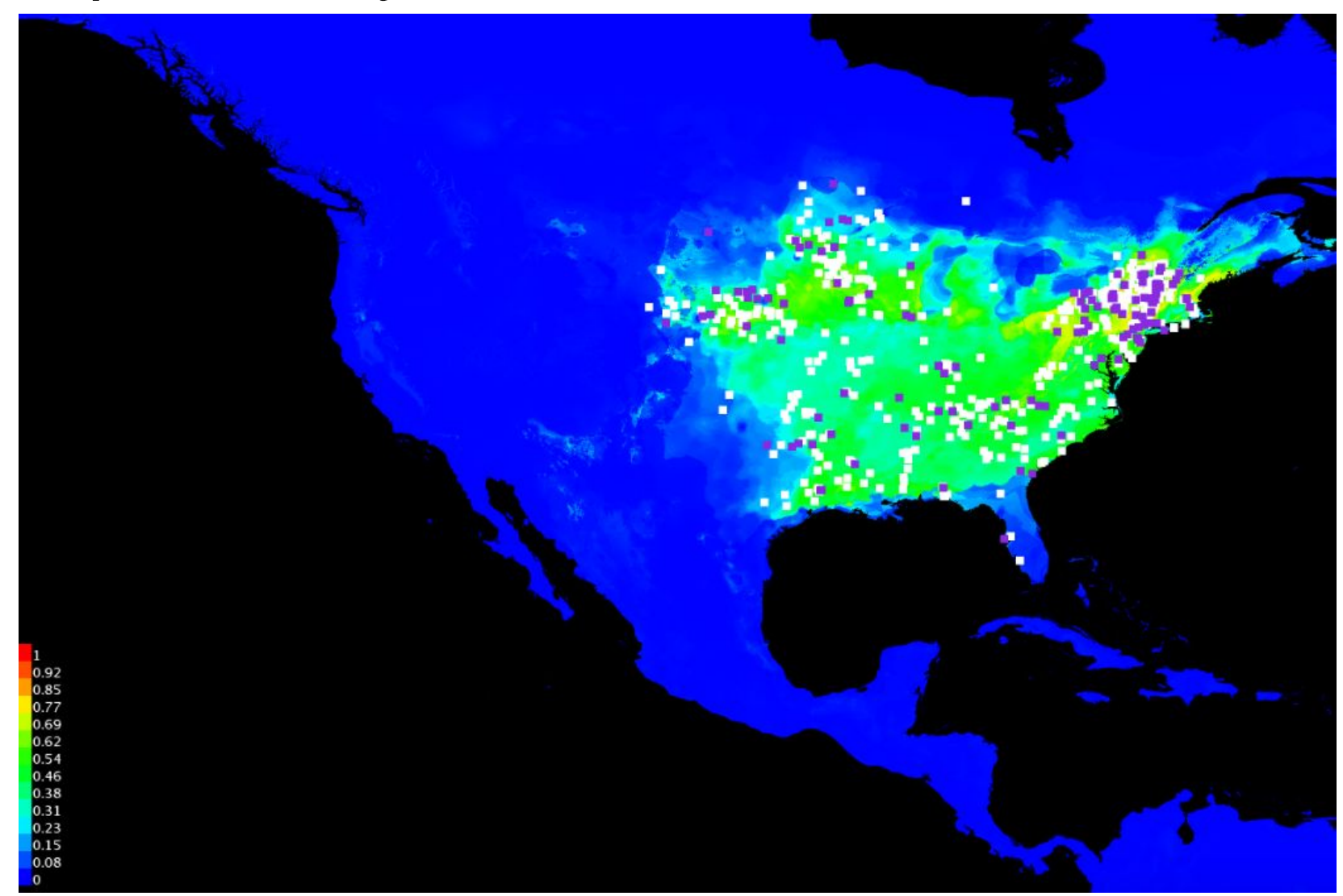


What is driving the change in predictions? 


\section{Data}

Increase in data points: Up to $56 \%$

Average number of records in each partition:

Prior to 1964: 138.4

1964-1989: 49.7

1990-2015: 882

Average number of unique localities in each partition: 597.6

Average year of collection: 1992.9 


\section{Conclusions}

- The Beatty Collection of Odonata can be used in identifying patterns in the distribution of mid-2oth century odonates

- Digitized collections data are critical for identifying species distribution changes

- Niche models should address the biases, variables, and numbers of specimens
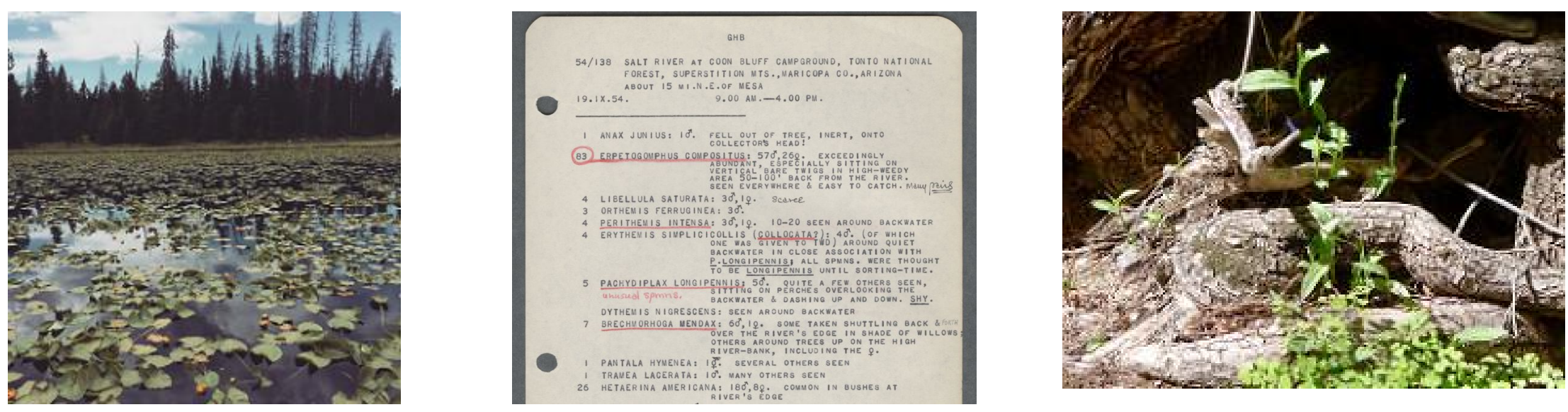


\section{Future Directions}

$\rightarrow$ Georeference other collections

$\rightarrow$ Incorporate larvae

$\rightarrow$ Use surface water data

$\rightarrow$ Combine edaphic factors data

$\rightarrow \quad$ Look at other possible disturbances

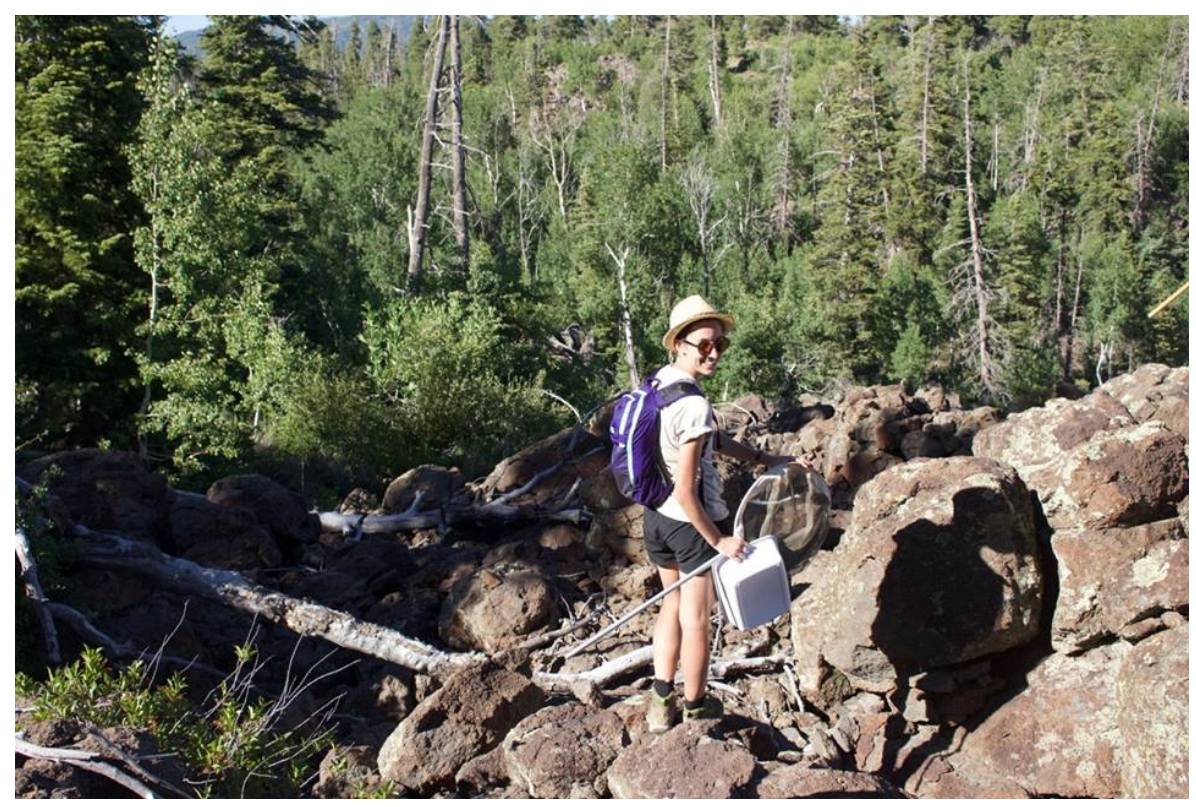




\section{Acknowledgements}
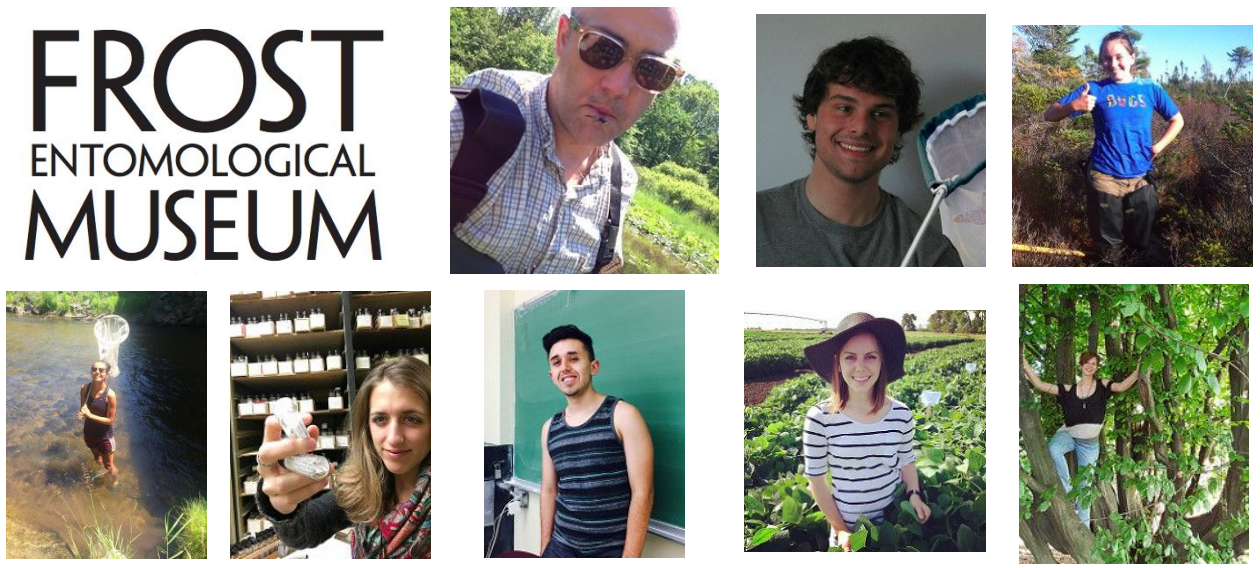

PennState University Libraries

ODONATA CENTRAL

TaxonWorks

This material is based upon work supported by the U. S. National Science Foundation, under Grant

Numbers DBI-1349356 and

EF-1400993. Any opinions, findings,

and conclusions or recommendations

expressed in this material are those of

the authors and do not necessarily

reflect the views of the National

Science Foundation.

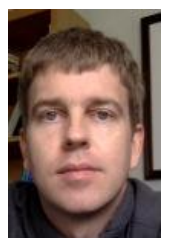

Matt Yoder 


\section{Questions?}

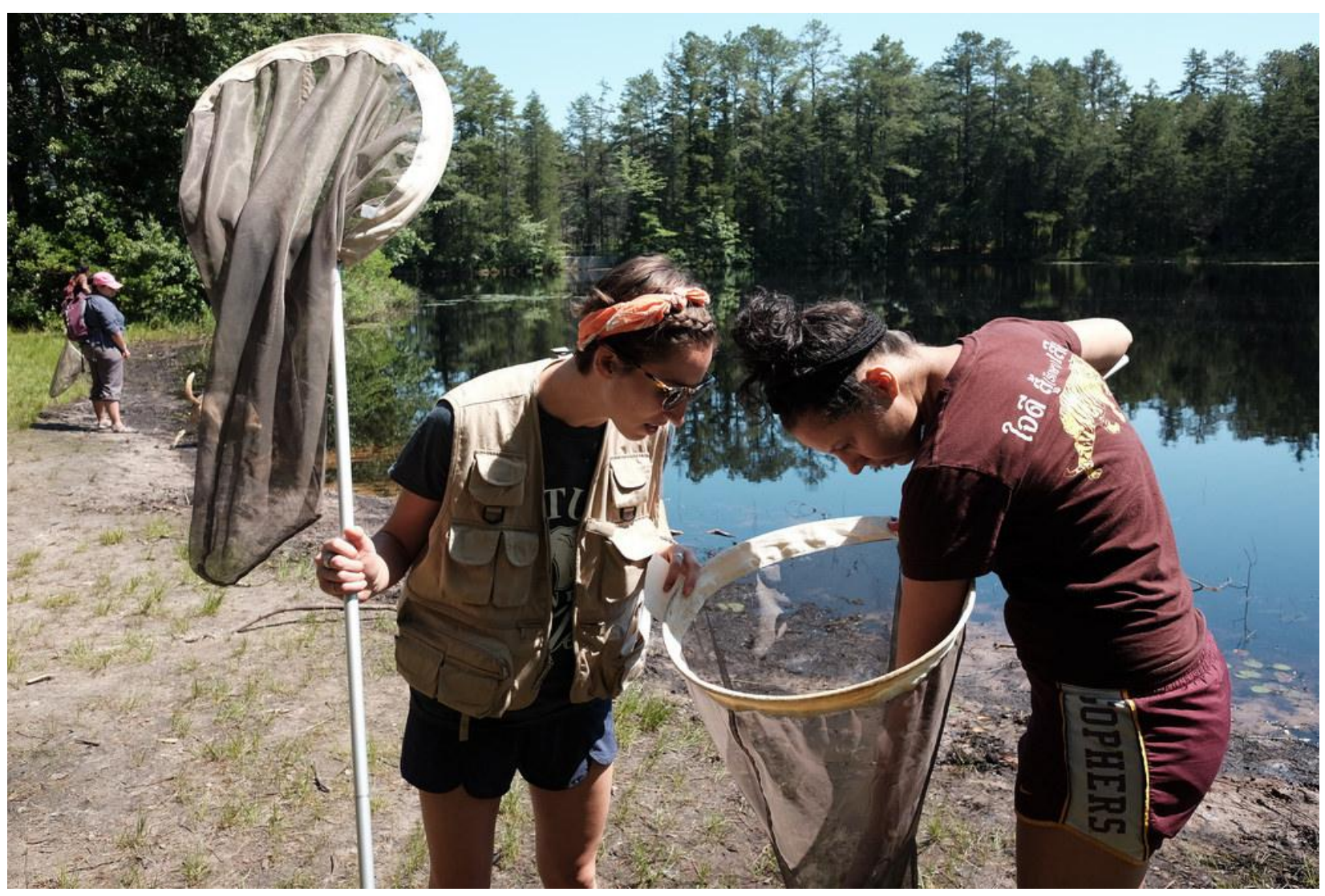

